\title{
Observation of Isomerization of an Azobenzene Derivative in Gold Nanoparticle Aggregates Using SERS
}

\author{
Jun Hec Yoon and Sangwoon Yoon

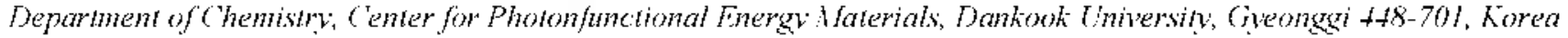
${ }^{*}$ E-mail: sangroonídidankook ach
Received October 9, 2009, iccepted October 28, 2009

Key Words: Photoisomerization. Gold nanoparticle aggregates, SERS, Azobenzene

Photoisomerization has fascinated scientists for decades. ${ }^{1}$ The light-induced molecular motion provides important information on the dy namics of molecules on the excited-state polential energy surfaces. It also las a wide range of applications including optical switches. light-driven devices. and crasable writing media. ${ }^{2}$ Azobenvene represents the most widely studicd photochromic molecule. Trans-Azoben/ene is more stable than its cis counterpart due to less sicric hindrance. Electronic transition of mans-Azobenzene to $S_{1}\left(\lambda_{\text {nाra }}=449 \mathrm{~mm}\right)$ or $S_{2}\left(\lambda_{\text {rllas }}=317 \mathrm{~nm}\right)$ states leads to the isomerization to cisAzobenzene will a quantum yicld of 0.25 and 0.10 . respectively ${ }^{4,5}$ So far, many experimental and theoretical studies have been performed on the dynamics of photoisomerization of azobellzene. (i-9 $^{-9}$

Novel metal nanoparticles and their aggregates provide unique environments for studying photochemistry. ${ }^{11.3}$ They act as an electron source for photo-induced charge transfer which opens a new reacion pathway in addition to the regular photochemistry of adsorbates on their surfaces. Furthermore. Surfaceenhanced Raman scattering (SERS) from nanoparticle aggregates provides extremely high sensitivity that allows one to probe submonolayer coverage of molecules.

Despitc many atlractive propertics of metal nanoparticle aggregates. studies on the photoisomerization of azobenzene are rare. ${ }^{11.12}$ The reason is probably that it is difficult to produce stable aggregates that maintain their morphologies during the period of experiments withoul precipitation. Another reason is a difficuly in probing the isomerization in aggregates. Since the absorption of gold or silver nanoparticles is so large that it overwhelms the absorption of azobertzenc. "3V-Vis absorption spectroscopy ty pically used to probe the isomerization in solution is inadequate for studying the isomerization in aggregates.

In thus communucation. we report the observation of photoisomerization of an azobcrizene derivative in gold nanoparicle (AuNP) aggregates using SERS. We synthesize an azobelzene derivative that can induce the formation of AuNP aggregates by adsorbing onto the surface of AuNPs. By the addition of a carefully controlled amount of the azobenzene derivative. we produce stable AuNP aggregates. SERS allows us to probe the trans-cis isomerization of the azobenzene derivatives.

The molecular structure of the sy nthesized a\%obenzene derivative ("AZO") is given below. AZO consists of a photosensitive azobenzene moiety and a long alkyl chain spacer group that provides a room for isonerization of the azobensene molety when adsorbed on the surfaces of AuNPs (Supporting Information).

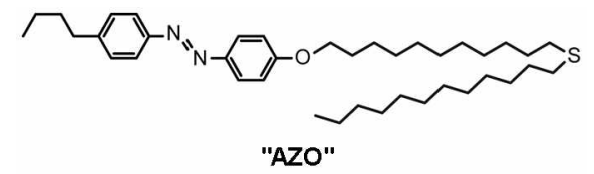

We first characterized photochemical properties of AZO in solution. The synthesized $\mathrm{AZO}$ is predominantly in the trans forn with an absorption at $3+9 \mathrm{~nm}$. Fig. 1(a) shows that upon irradiation at $365 \mathrm{~mm}\left(3 \mathrm{~mW} / \mathrm{cm}^{-1}\right)$ for 30 min the 349 -rum band ranishes and the absorption at $4+6$ lum rises (Lamp ON). indicating that the photoisomeriation from trans to cis has occurred. When we turn off the lamp and measure the UV-Vis absorption

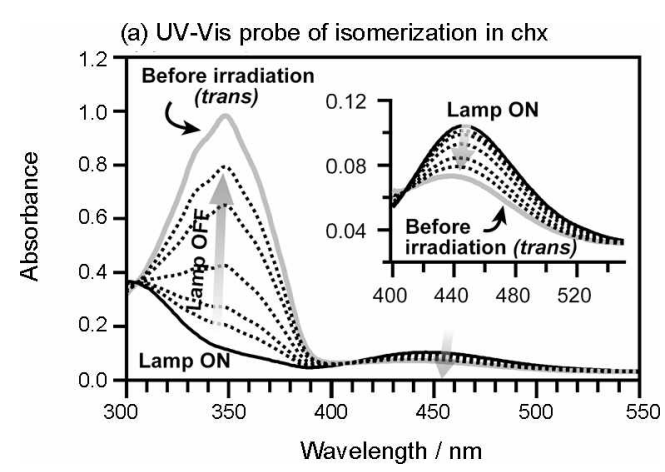

(b) Raman probe of isomerization in DCM

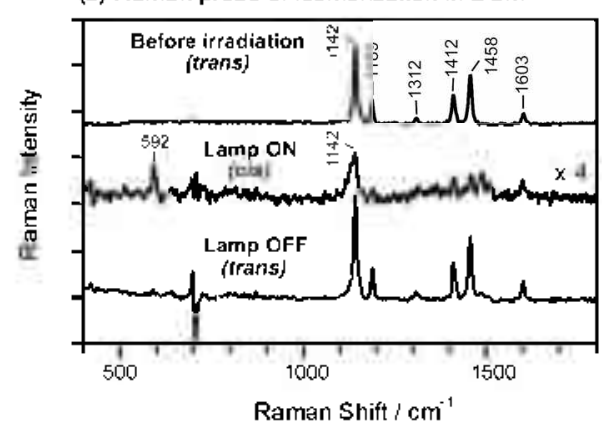

Figure 1. (a) UV-Vis absorption spectra ol A $\angle O$ in cyclohexalle (23 $\mu \mathrm{M}$ ) be lore irradiation, after irradiation at $365 \mathrm{~mm}$ lor 30 min (Lamp ON), and after the subsequent lamp-oft for $4,8,16,32$, and 60 min. (b) Ramen spectra of AZO in dichloromethane ( $1 \mathrm{mM}$ ) betore irradiation, atter irradiation for $30 \mathrm{~min}$ ( (T amp $O N$ ) and atter the subsequent lamp-oti tor $3 \mathrm{~h}$. The solvent spectra have boen subtracted. 
(a) Isomerization in AuNP Aggregates

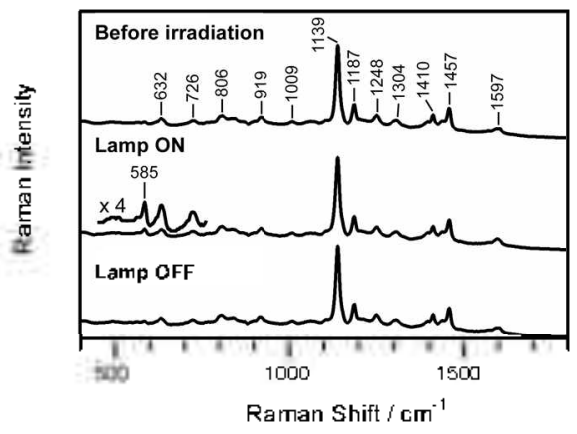

(b) Photoswitching $\left(585 \mathrm{~cm}^{-1}\right)$

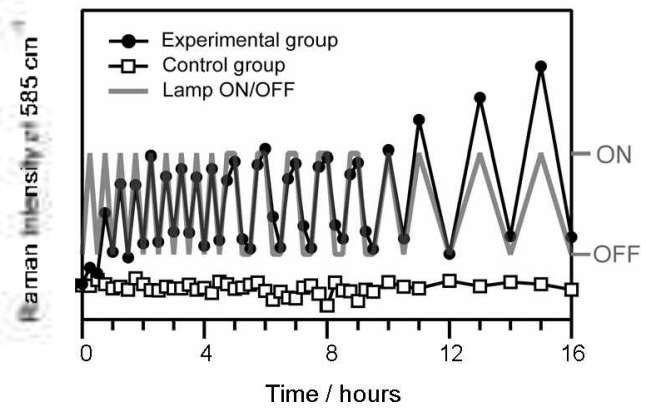

Figun 2. (a) SFRS spectra of $\triangle 7 O$ in $\triangle u N P$ aggregates before irradiation, after irradiation at $365 \mathrm{~mm}$ for 30 min, and atter the subsequent lamp-otf tor 50 min. (b) The change of the Raman intensity at $585 \mathrm{~cm}^{-1}$ (cis band) of the experimental and control oroup as the 365 -11m lamp is switched on and ofl repuentexily: The control group is the sanple taken from the same batch as the experimental group, but subject to no irradiation.

spectra as time elapses, the $349-\mathrm{nm}$ trons band is gradually restored and the $449-1 u n$ cis band becomes subdued. suggesting that the back-isomeri/ation by a room light slow ly occurs. ${ }^{1.4}$

Raman spectra measurements for more concentrated solution of AZO in dichloromethane ( $1 \mathrm{mM}$ ) show that upon irradiation at 365 mun. the overall Raman intensily decreases and a new band at $592 \mathrm{~cm}^{-1}$. assigned to the mixed CNNC and CCCH torsional mode of the azobcnzene moicty in the cis form. appears." Because other bands are either weak or overlapped with the trans bands. the $592-\mathrm{cm}^{-1}$ band is an important signature of isomerization. Temination of the irradiation gives rise to the Raman spectrum of the trans isomer (Lamp OFF).

We prepared AuNPs with an average diameter of $40 \mathrm{lum}$ by the citrate-reduction of $\mathrm{Au}^{3}$ ions. following the method developed by Frens and coworkers. ${ }^{15}$ Adsorption of AZO onto the surface of AuNPs via the fonnation of a Au-S bond induces the aggregation of AuNPs. ${ }^{16}$ Addition of $0.8 \mu \mathrm{M}$ of AZO produces stable AuNP aggregates wilhout precipitation for at least 16 h (Supporting Infornation), A new absorption band at $~ 800$ nin arising from the dipolar coupling of surface plasmons between individual AuNPs in the aggregates offers an opportunity for the SERS probe of the isomerization because the surface plasmon absorption is resonant with our Raman excitation laser (785 $\mathrm{iml})$. $^{-}$

Indeed. Raman spectra obtained from the aggregates are greatly enhanced as shown in Fig. 2(a). Note that the spectrum is produced by only $0.4 \mu \mathrm{M}$ of $\mathrm{AZO}$ used to form the aggregates. The SERS spectrum of rans-AZO from the AuNP aggregates is similar to the Raman spectra of AZO in solution except that more low frequency bands are observed for the former.

Upon irradiation at $365 \mathrm{~mm}\left(3 \mathrm{~mW} / \mathrm{cm}^{2}\right)$ for $50 \mathrm{~min}$ the characleristic $c \%$ Raman band appears at $585 \mathrm{~cm}^{-1}$. indicating that the isomerization of AZO has occurred in the aggregates. Since other Raman peaks from the trans are still observed, the isomerization quantum y ield seems rather low. When we leave the sample under a room light after the irradiation. cis-AZO isomerizes back to the mans fonn (Lamp OFF).

The photoisomerization reaction in AuNP aggregates is lighly reversible. We demonstrate the photoswitching of AuNP aggregates in Fig. 2(b). We turned on and of the lamp repeatcdly and measured the Raman intensity of the signature cis band at $585 \mathrm{~cm}^{-1}$. Figure 2(b) shows that the Raman intensity at $585 \mathrm{~cm}^{-1}$ increases as the lamp is turned on and decreases as the lamp is switched off. As the irradiation time is lenglhened ( $10 \sim 16$ h region). the Raman intensity increases exponentially. In contrast, the Raman intensity of the control group without irradiation remains unchanged, indicating that the signal change we observed is indeed from photoreaction. not from any ellects of aggrcgation.

Further quantitative investigations on the isomerization rate and the effect of other experimental parameters on the rate are underway in our laboraton.

Acknowledgments. This work was supported by the Dankook University research fund (2008).

Supporting Infomation. Experimental method and Raman spectral assignments are available via the internet at http:// ww.kcsnct.or.kr/bkcs

\section{References}

1. Durr. H.: Bouras-J aurent. H. Photochromism: Holectrles and Sistems: Flservier: New York, 1990.

2. Ikeda, T: Tsutsumi, O. Sciunce 1995, 268, 187 .

3. Klaj11, R.: Wesson, P. T. Bishop, K. J. M.: Grzybowski, B. A. Angew' (hent. Int. Ed. 2009, 48,1

4. Bortolus. P.: Monti, S. J. Phys Chem 1979, 83,648.

5. Rau, I I.: Luddecke, L. J. Im. Chem. Soc 1982, 104, 1616.

6. Chang, C. W.: Lu, Y. C.. Wang, T. T.: Diau, E. W. G. J. Im. Chen. Soc 2004. 126, 10109

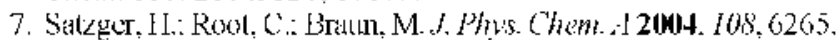

8. Crecca, C. R: Roitberg, A. E. J. Phrs ( Wem t 2006, 10, 8188.

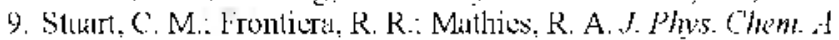
2007, 111,12072

10. Kamat, P. V.J. Phys (hem. B 2002, 106, 7729.

11. Yang, S. I.: Kim, K.-H.: Kand D. Joo, S.-W. Photochem Photobio. Sct. $2009,8,31$

12. Iung, Y. M.: Tashiro, H.: Ikeda, T: Ozaki, Y. Appl Spectrosc. $2001,55,344$

13. lain, P. K.: Ilume, X.: L1-Sayed, 1. 11.: L1-Sayed, M. A. Ace. Chen. Res. $2008,+1,1578$

14. In a dark room, the backisomerization was much slower

15. lirens, G. Kature Phis. Sai 1973, 2H1. 20.

16. Yoon, I. II.: Park I. S.: Yoon, S. Langmim 2009), 25, 12475

17. lensen, T.: Kelly, L .; Lazarides, A.: Schatz, G. C.J. Chrster Sci. 1999, 10.295. 